Original

\title{
Overexpression of Cyclin D1 and p53 in N-ethyl-N- nitrosourea and Ethinylestradiol-induced Uterine Proliferative Lesions in Heterozygous p53 Deficient CBA Mice
}

\author{
Takeo Shimo $^{1}$, Junichi Katayama ${ }^{1}$, Akemi Saito ${ }^{1}$, Eisuke Morohashi ${ }^{1}$, Yasuhiro Tega ${ }^{1}$, \\ Yasuji Aoki ${ }^{1}$, and Osamu Nagata ${ }^{1}$
}

${ }^{1}$ Research Department, Research \& Development Division, Hokuriku Seiyaku Co., Ltd., Fukui 911-8555, Japan

\begin{abstract}
Immunohistochemical investigations on the expression of PCNA, cyclin D1, and p53 were carried out on uterine proliferative lesions of heterozygous $p 53$ deficient CBA mice $[p 53(+/-)$ mice] given an intraperitoneal injection of $120 \mathrm{mg} / \mathrm{kg}$ body weight of N-ethyl-N-nitrosourea (ENU) followed by diet containing 1 or $2.5 \mathrm{ppm}$ ethinylestradiol (EE) for 26 weeks. Histopathologically, uterine proliferative lesions were classified as endometrial stromal tumors (polyps and sarcomas), atypical hyperplasias (clear and basophilic cell types), an adenocarcinoma, and glandular hyperplasias. The PCNA labeling index (LI) for endometrial stromal tumors was very high in some areas of sarcomas in the ENU+EE groups, but very low elsewhere and in polyps, with significant differences. The PCNA LI for clear cell type atypical hyperplasias was also significantly greater than for glandular hyperplasias or basophilic cell type atypical hyperplasias. Values were comparable for each proliferative lesion between the ENU+2.5 ppm EE and ENU+1 ppm EE groups. In addition one adenocarcinoma with markedly high proliferation was seen with the higher dose of EE. Overexpression of cyclin D1 was also apparent in actively proliferating areas of stromal sarcomas and clear cell type atypical hyperplasia, percentages of positive cells being $67-100 \%$. In contrast, $p 53$ was only expressed in markedly proliferative areas of stromal sarcomas at percentages of 69 and 89 in the two groups. The present study indicates that cyclin D1 and p53 may play key roles in uterine transformation of proliferative lesions in $p 53(+/-)$ mice.

(J Toxicol Pathol 2001; 14: 1-8)
\end{abstract}

Key words: N-ethyl-N-nitrosourea, ethinylestradiol, uterine tumorigenesis, cyclin D1, p53, heterozygous p53 deficient mice

\section{Introduction}

It is well known that $p 53(+/-)$ mice are higly sensitive to genotoxic carcinogens ${ }^{1,2}$. The proposed roles of $p 53$ in genome stability and its loss in tumorigenesis are supported by the fact that $p 53(+/-)$ mice with hetero-alleic loss may develop tumors early in life ${ }^{3,4}$. To confirm advantages of these mice for short-term alternative carcinogenicity testing models, we have performed a series of uterine tumorigenesis studies, first demonstrating that uterine endometrial stromal sarcomas can be induced in $p 53(+/-)$ mice with a single intraperitoneal injection of N-ethyl-N-nitrosourea (ENU) ${ }^{5}$. In a second study, ENU+ethinylestradiol (EE) administration to $p 53(+/-)$ mice resulted in enhanced

Received: 25 August 2000, Accepted: 17 November 2000 Mailing address: Takeo Shimo, Research Department, Research \& Development Division, Hokuriku Seiyaku Co., Ltd., 37-1-1, Inokuchi, Katsuyama, Fukui 911-8555, Japan

TEL: 81-779-88-8006 FAX: 81-779-88-8022

E-mail: takeo.shimo@hokuriku-seiyaku.co.jp induction of clear cell type of atypical hyperplasias and an adenocarcinoma in addition to stromal sarcomas ${ }^{6}$.

The $p 53$ gene is the most well-known negative regulator of the cell cycle. Mutations of the $p 53$ gene have been associated with tumors of a wide variety of human organs, including the urinary bladder ${ }^{7}$, breast ${ }^{8}$, esophagus ${ }^{9}$, stomach $^{10}$, lung ${ }^{11}$, uterus ${ }^{12}$, and prostate ${ }^{13}$. It has been demonstrated that the $p 53$ suppressor protein exerts checkpoint control at the $\mathrm{G} 1 / \mathrm{S}^{4,14}$ and $\mathrm{G} 2 / \mathrm{M}^{15}$ transitions. Cyclins also regulate cell cycle progression by controlling the activities of cyclin-dependent kinases at various checkpoints ${ }^{16,17}$. Several studies have indicated that cyclin D1 plays an important role as one of the main regulatory proteins controlling the normal progression of cells through $\mathrm{G} 1^{18}$. Amplification in its gene has been implicated in the development of human tumors, including liver cancer ${ }^{19}$, malignant lymphoma ${ }^{20}$, breast cancer ${ }^{21}$, and esophageal cancer $^{22}$.

The present immunohistochemical study was performed to investigate whether cyclin D1 and $p 53$ are 
upregulated in uterine proliferative lesions induced by ENU and $\mathrm{EE}$ in $p 53$ (+/-) mice.

\section{Materials and Methods}

\section{Animals and housing}

The present immunohistochemical study was performed using formalin-fixed and paraffin-embedded sections of uterine proliferative lesions obtained in our previous experiment ${ }^{6}$. The animals used were heterozygous female p53 deficient CBA mice [p53 (+/-) mice], F1 offspring of heterozygous $p 53$ deficient C57 BL/6J male mice, back-crossed with CBA female mice, having an inactivated exon 5 in one $p 53$ allele. Thirty female $p 53(+/-)$ mice, 6 weeks of age, were purchased from Oriental Yeast Co., Ltd (Tokyo, Japan). Through the acclimatization and experimental periods, animals were housed at a maximum of 5 per cage in plastic cages with absorbent hardwood bedding (White Flakes, Charles River Inc., Tokyo, Japan) in an airconditioned animal room (room temperature, $24 \pm 2{ }^{\circ} \mathrm{C}$; relative humidity, $60 \pm 10 \%$; lighting cycle, 12 light/12 dark). CRF-1 powder diet (Oriental Yeast Co., Ltd.) and tap water available ad libitum via automatic stainless steel dispensers.

\section{Test materials}

ENU and EE were both purchased from Nacalai Tesque Inc. (Kyoto, Japan).

\section{Experimental design}

Thirty female $p 53$ (+/-) mice were divided into 2 groups consisting of 15 animals each. All received an intraperitoneal injection of $120 \mathrm{mg} / \mathrm{kg}$ body weight of ENU, followed by diet containing $1 \mathrm{ppm} \mathrm{EE}$ (ENU+1 ppm EE) or 2.5 ppm EE (treated with 5 ppm EE for the first 4 weeks and thereafter reduced to $2.5 \mathrm{ppm}$ EE because of body weight decrease) $(E N U+2.5 \mathrm{ppm} E E)$, for 26 weeks. The carcinogen, ENU, was dissolved in physiological saline and filtered through a Millipore filter (MILEX-GV, Japan Millipore Ltd., Tokyo, Japan) before intraperitoneal injection at a dose of $120 \mathrm{mg} / \mathrm{kg}$, selected based on the results of our previous study ${ }^{5}$ EE was routinely mixed with powder diet for administration.

\section{Histopathology and immunohistochemical examination}

After the end of the 26-week experimental period, the animals were subjected to a full autopsy, then a wide variety of organs and tissues were dissected out and fixed in $10 \%$ neutral buffered formalin. Each uterus was processed routinely, embedded in paraffin, sectioned at $4-5 \mu \mathrm{m}$, and stained with hematoxylin and eosin (H-E) for microscopic examination. In addition, immunohistochemical staining was applied for proliferating cell nuclear antigen (PCNA), p53 and cyclin D1. The sections were pretreated by microwaving once and twice for $5 \mathrm{~min}$ for PCNA, and p53 and cyclin D1, respectively. Endogenous peroxidase was inactivated using $3 \% \mathrm{H}_{2} \mathrm{O}_{2}$, and non-specific binding of proteins was blocked with normal goat serum. The sections were then incubated with one of the following primary antibodies overnight at $4{ }^{\circ} \mathrm{C}$ : monoclonal antibody against PCNA (DAKO, Glostrup, Denmark), p53 (CM1, Novocastra Labs., Newcastle, UK) and cyclin D1 (IBL, Japan) at dilutions of $1: 100,1: 500$ and 1:300, respectively. Immunolocalization was visualized using the avidin-biotin peroxidase complex method (DAKO) with 3, 3'diaminobenzidine as the chromogen and hematoxylin for counterstaining. The number of PCNA positive cells per 100 cells in each proliferative lesion was counted in three different areas and the labeling index (PCNA LI) was calculated as a percentage value. The animals used for counting of PCNA LI were selected randomly, maximum 7 per lesion.

\section{Statistical analysis}

The incidences of uterine proliferative lesions observed were analyzed by the Fisher's exact test. Significant differences between two groups were assessed. Data for the PCNA LI were used to generate mean and standard deviation values, and significant differences between uterine nonepithelial or epithelial proliferative lesions were then analyzed with the Student's $t$ test. Similarly, differences between counterpart uterine proliferative lesions in the two treated groups were tested for significance.

\section{Results}

Histopathologically, uterine proliferative lesions induced by ENU+ EE treatments to p53 (+/-) mice were classified into endometrial stromal sarcomas, stromal polyps, an adenocarcinoma, atypical hyperplasias, and glandular hyperplasias. Endometrial stromal sarcomas were composed of sheets, bundles, and occasionally whorls of spindle-shaped cells with large pale an chromatin-rich nuclei, the latter associated with abnormal mitoses and marked cellular atypia (Fig. 1). Endometrial stromal polyps were pedunculated masses protruding into the uterine lumen consisting of loosely organized endometrial stromal cells with scattered cystic endometrial glands and welldifferentiated cuboidal epithelial cells on the surface. The adenocarcinoma was characterized by diffuse glandular proliferation of large, atypical epithelial cells with clear cytoplasm, with invasion into surrounding tissues (Fig. 2). Atypical hyperplasias were small proliferative foci of endometrial glandular epithelium with atypia and classified into clear and basophilic cell types (Fig. 3). Glandular hyperplasias were composed of increased numbers of endometrial glands with occasional cysts.

The incidences of endometrial stromal tumors were $85 \%$ (sarcomas, 64\%; polyps, $21 \%$ ) and $87 \%$ (sarcomas) in ENU+1 ppm EE and ENU+2.5 ppm EE groups, respectively (Table 1). Clear cell type atypical hyperplasias were seen at incidences of 14 and $60 \%$ in ENU+1 ppm EE and ENU+2.5 ppm EE groups, respectively, with a significant difference 


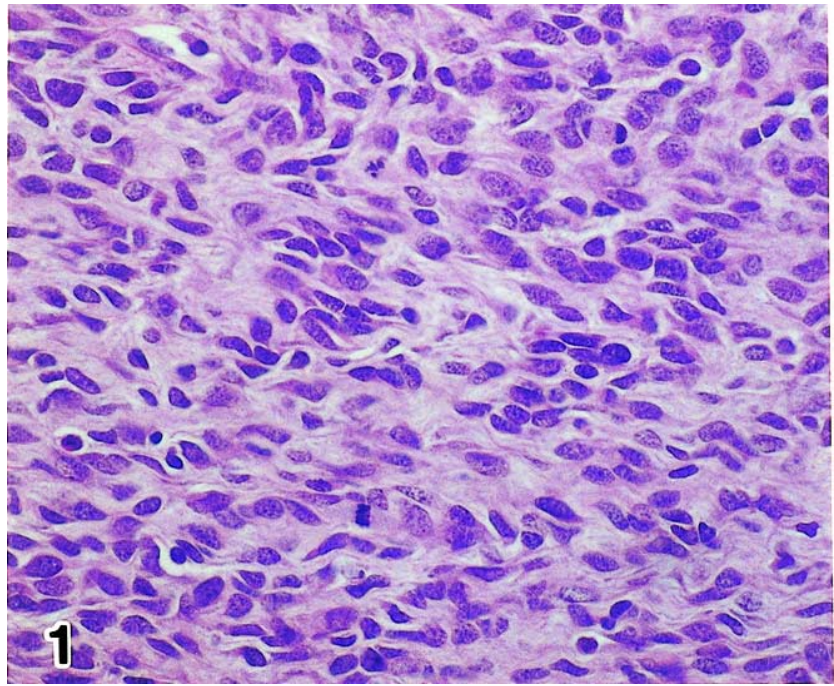

Fig. 1. Uterine endometrial stromal sarcoma from a $p 53$ (+/-) female mouse given ENU+2.5 ppm EE and sacrificed at week 26. Note marked proliferation of spindle-shaped or pleomorphic cells with prominent atypical nuclei and mitoses. H-E staining, $\times 330$.

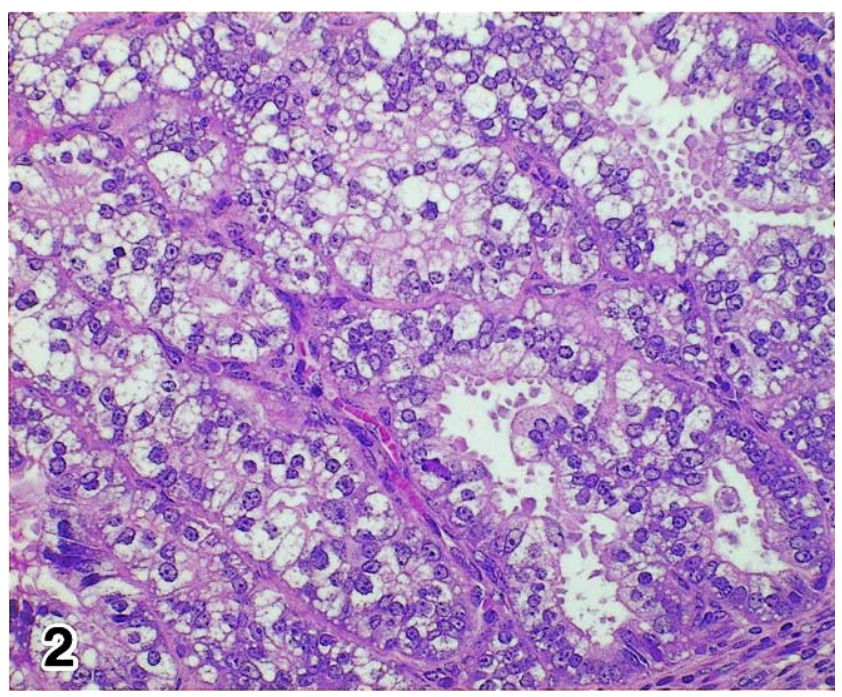

Fig. 2. Uterine adenocarcinoma from a $p 53(+/-)$ female mouse given ENU $+2.5 \mathrm{pm}$ EE and sacrificed at week 26 . Note diffusely glandular proliferation of large, atypical epithelial cells with clear cytoplasm, invading into adjacent tissues. H-E staining, $\times 200$.

between the two and the basophilic cell type at 57 and $60 \%$. Only the one $p 53(+/-)$ mouse in the ENU+2.5 ppm EE group had an adenocarcinoma (7\%). In addition, glandular hyperplasias were induced at incidences of 79 and $60 \%$ in the two treated groups.

The PCNA LIs in highly proliferative areas with marked cell atypia of stromal sarcomas were $37.7 \pm 5.5$ and $38.3 \pm 4.3$ in ENU+1 ppm EE and ENU+2.5 ppm EE groups, respectively, and $9.6 \pm 2.9$ and $9.3 \pm 2.8$, in weakly proliferative regions with slight cell atypia, with significant
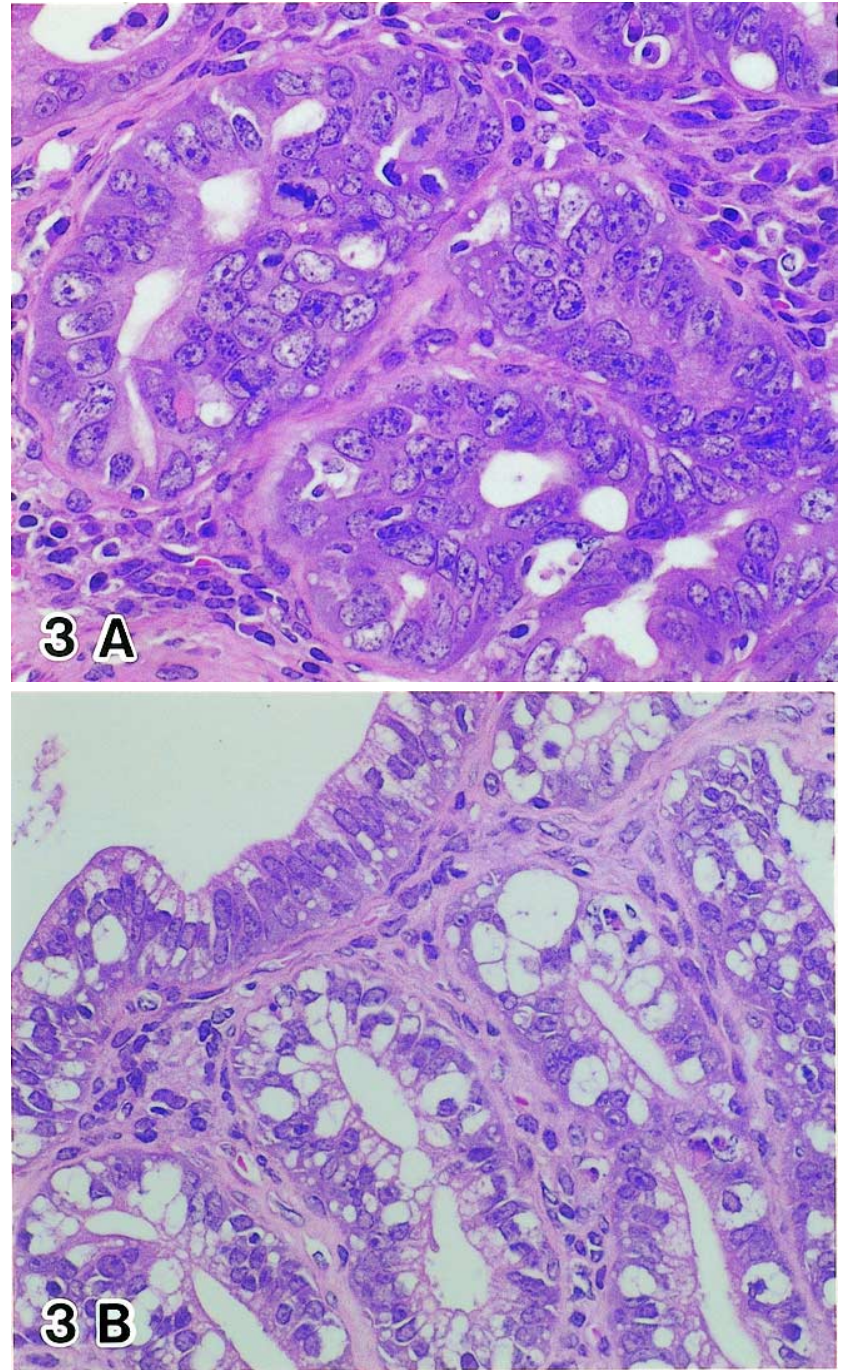

Fig. 3. Uterine atypical hyperplasias of endometrial glands from a p53 (+/-) female mouse given ENU+2.5 ppm EE and sacrificed at week 26. Note histologic features characterized by proliferative foci of atypical endometrial glandular epithelium with basophilic cytoplasm (A) and clear cytoplasm (B). H-E staining, $\times 330$.

Table 1. Incidences of Uterine Proliferative Lesions in $p 53(+/-)$ Mice Treated with EE for 26 Weeks after ENU Initiation

\begin{tabular}{lcc}
\hline \multirow{2}{*}{ Proliferative lesions } & \multicolumn{2}{c}{$p 53(+/-)$} \\
\cline { 2 - 3 } & ENU+1 ppm EE & ENU+2.5 ppm EE \\
\hline Number of animals & 14 & 15 \\
Endometrial stromal polyp & $3(21)$ & $13(87)$ \\
Endometrial stromal sarcoma & $9(64)$ & $9(60)$ \\
Glandular hyperplasia & $11(79)$ & $9(60)^{*}$ \\
Atypical hyperplasia & & $9(60)$ \\
$\quad$ clear cell type & $2(14)$ & $1(7)$ \\
$\quad$ basophilic cell type & $8(57)$ & \\
Adenocarcinoma & & \\
\hline
\end{tabular}

*: Significantly different from the relevant ENU+1 ppm EE group at $\mathrm{p}<0.05$.

Values in parenthesis represent percentage. 
Table 2. PCNA LIs and Overexpression of Cyclin D1 and $p 53$ in Uterine Proliferative Lesions in $p 53$ (+/-) Mice Treated with EE for 26 Weeks after ENU Initiation

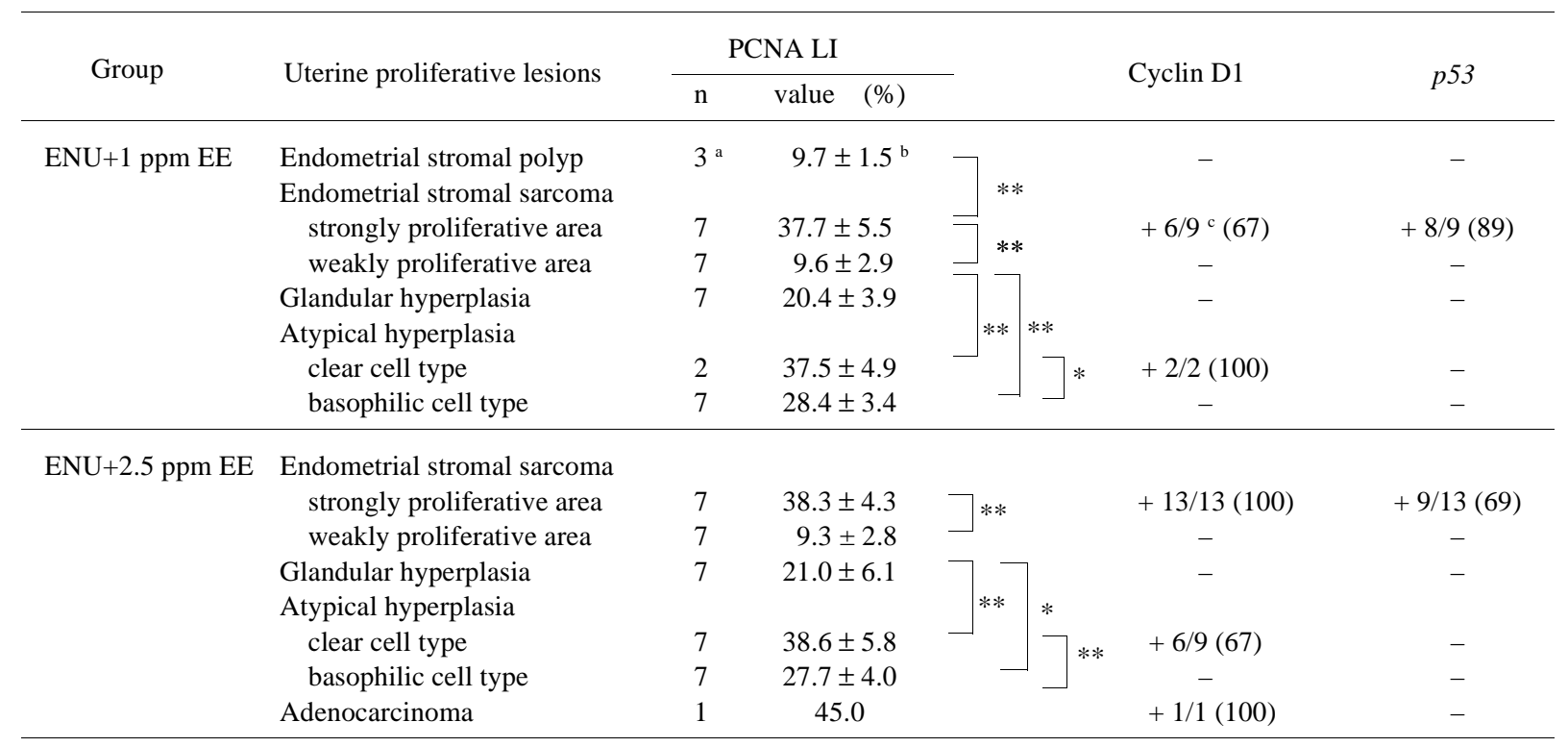

*,**: Significantly different between the designated lesions at $\mathrm{p}<0.05$ and 0.01 , respectively (Student's $t$ test).

a: No. of animals with lesions counted for PCNA LI was limited to 7.

$\mathrm{b}$ : The value represents Mean $\pm \mathrm{SD}$.

c: No. of animals with positive reactions/No. of animals with lesions.

Values in parentheses are percentages.

-: No positive reactions detected.
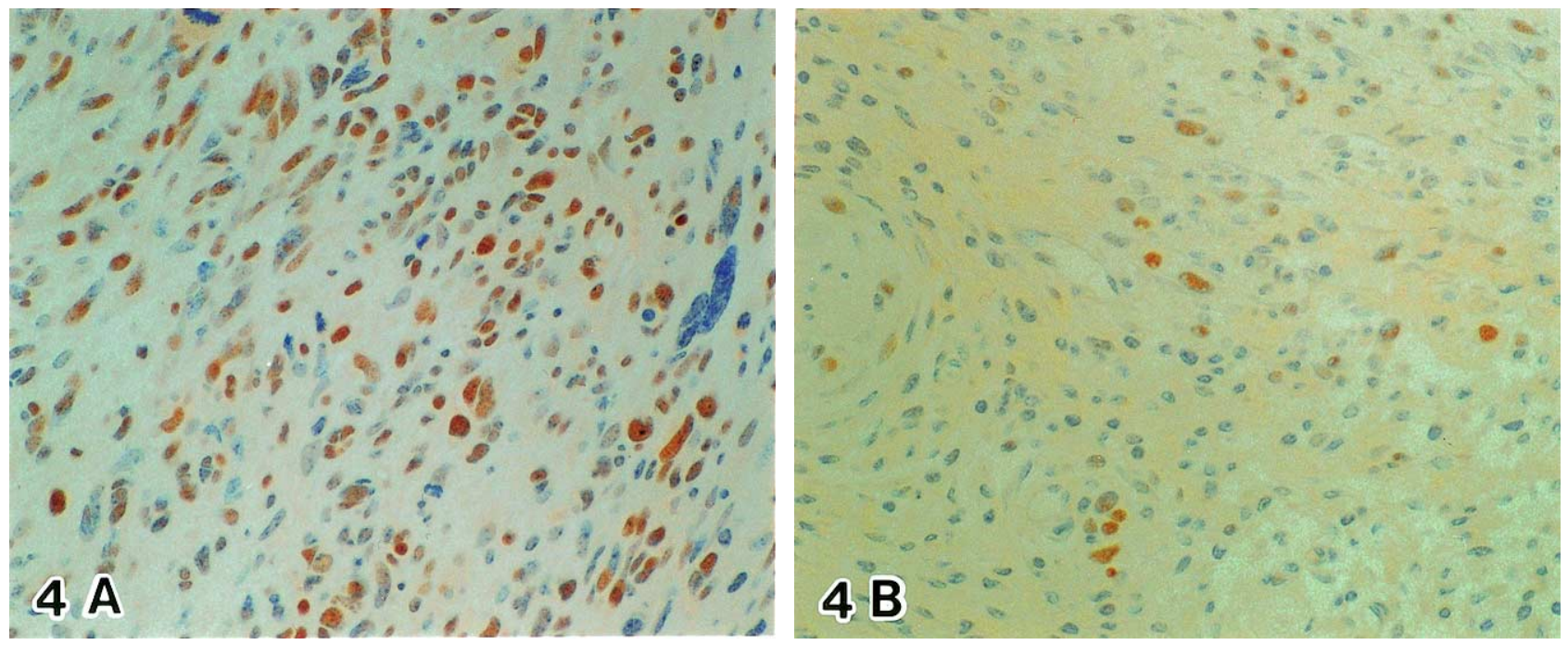

Fig. 4. Immunohistochemistry for PCNA in a uterine endometrial stromal sarcoma from a $p 53$ (+/-) female mouse given ENU+2.5 ppm EE and sacrificed at week 26. Note the markedly high PCNA LI in the strongly proliferative area (A) and the low PCNA LI in the weakly proliferative area (B). PCNA immunostaining, $\times 330$.

differences between the two (Table 2, Fig. 4). That for polyps $(9.7 \pm 1.5)$ observed only in the ENU+1 ppm EE group, was also relatively low. The PCNA LIs for clear cell type atypical hyperplasias were $37.5 \pm 4.9$ and $38.6 \pm 5.8$ in ENU+1 ppm EE and ENU+2.5 ppm EE groups, respectively (Fig. 5), including one adenocarcinoma (45) in the latter group. Their values attained significant differences from those of glandular hyperplasias $(20.4 \pm 3.9$ and $21.0 \pm 6.1)$ or basophilic cell type of atypical hyperplasias ( $28.4 \pm 3.4$ and $27.7 \pm 4.0$ ). Comparison of these latter also revealed significant differences between them in both groups.

Cyclin D1 was overexpressed in 6 of 9 cases (67\%) and 13 of 13 cases $(100 \%)$ in strongly proliferative areas of stromal sarcomas in the ENU+1 ppm EE and ENU+2.5 ppm EE groups (Table 2, Fig. 6), respectively, and in 2 of 2 $(100 \%)$ and 6 of $9(67 \%)$ clear cell type atypical hyperplasias 


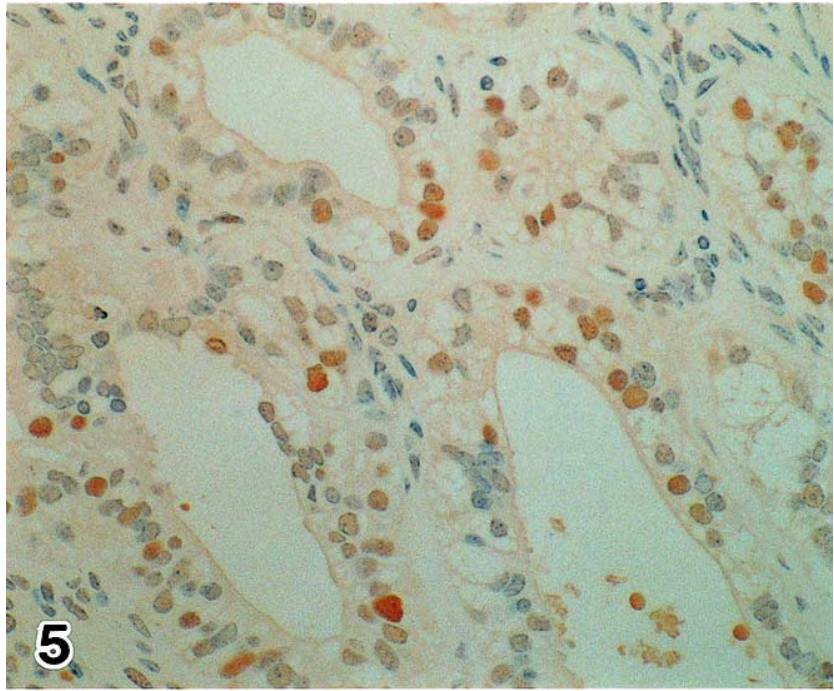

Fig. 5. Immunohistochemistry for PCNA in a clear cell type uterine atypical hyperplasia of endometrial glands from a $p 53(+/-)$ female mouse given ENU+2.5 ppm EE and sacrificed at week 26. Note the markedly high PCNA LI. PCNA immunostaining, $\times 330$.

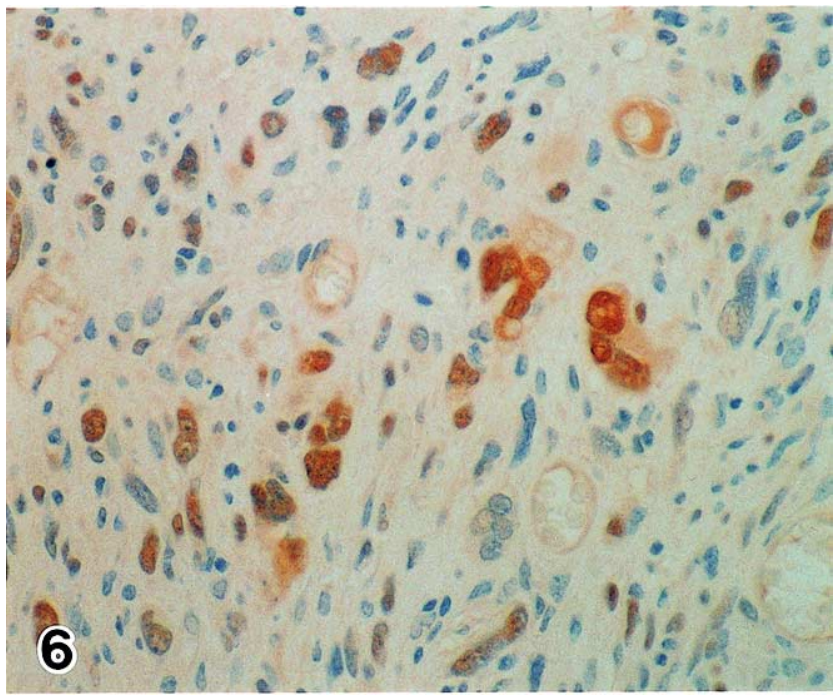

Fig. 6. Immunohistochemistry for cyclin D1 in a uterine endometrial stromal sarcoma from a $553(+/-)$ deficient female mouse given ENU+2.5 ppm EE and sacrificed at week 26. Note overexpression of cyclin D1 in the strongly proliferative area. Cyclin D1 immunostaining, $\times 330$.

(Fig. 7), as well as the one adenocarcinoma in the ENU+2.5 ppm EE group (Fig. 8). Overexpression of $p 53$ in strongly proliferative areas of stromal sarcomas was seen at incidences of 8 of $9(89 \%)$ and 9 of $13(69 \%)$ in the ENU+1 ppm EE and ENU+2.5 ppm EE groups, respectively (Table 2, Fig. 9).

\section{Discussion}

The present results provide new evidence that $p 53$ is

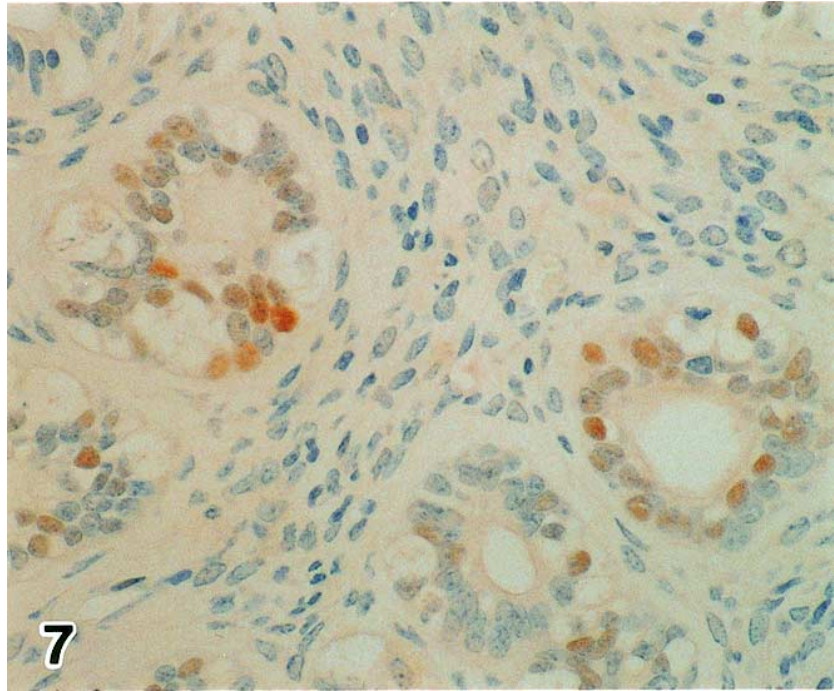

Fig. 7. Immunohistochemistry for cyclin D1 in a clear cell type uterine atypical hyperplasia of endometrial glands from a $p 53$ $(+/-)$ female mouse given ENU+2.5 ppm EE and sacrificed at week 26. Note overexpression of cyclin D1. Cyclin D1 immunostaining, $\times 330$.

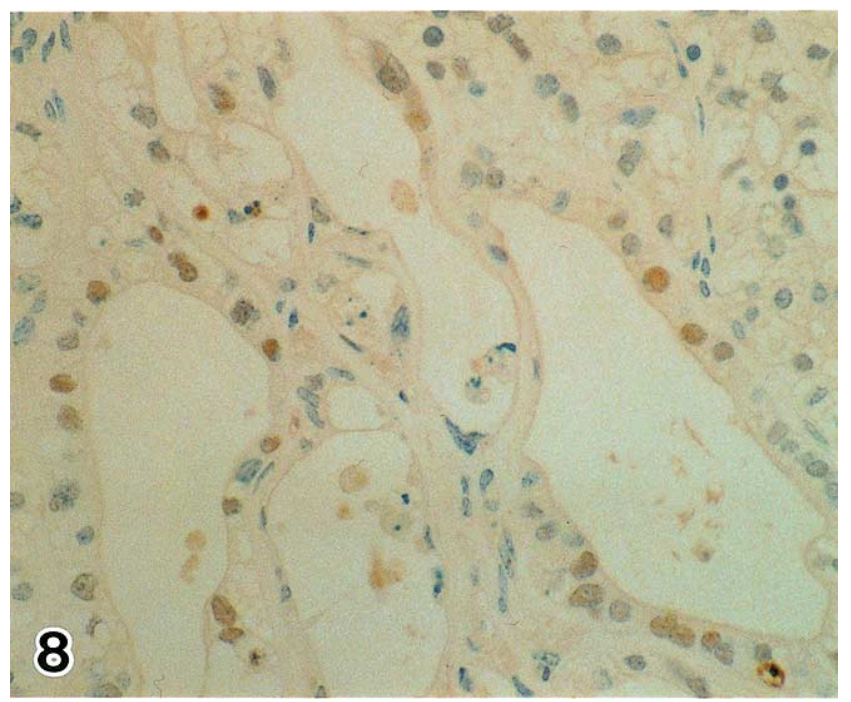

Fig. 8. Immunohistochemistry for cyclin D1 in the uterine adenocarcinoma from a $p 53(+/-)$ female mouse given ENU+2.5 ppm EE and sacrificed at week 26. Note marked overexpression of cyclin D1 in the adenocarcinoma. Cyclin D1 immunostaining, $\times 330$.

overexpressed, along with cyclin D1 in strongly proliferative areas of uterine stromal sarcomas. A link with cyclin D1 was further observed for clear cell type atypical hyperplasias including one clear cell type adenocarcinoma, with markedly high PCNA LIs. Interestingly, stromal sarcomas also contained areas with very low PCNA labeling, comparable to that of stromal polyps. The results are generally in line with an immunohistochemical study of formaldehydeinduced rat nasal squamous cell carcinomas which revealed that the presence, pattern, and distribution of $p 53$ staining 


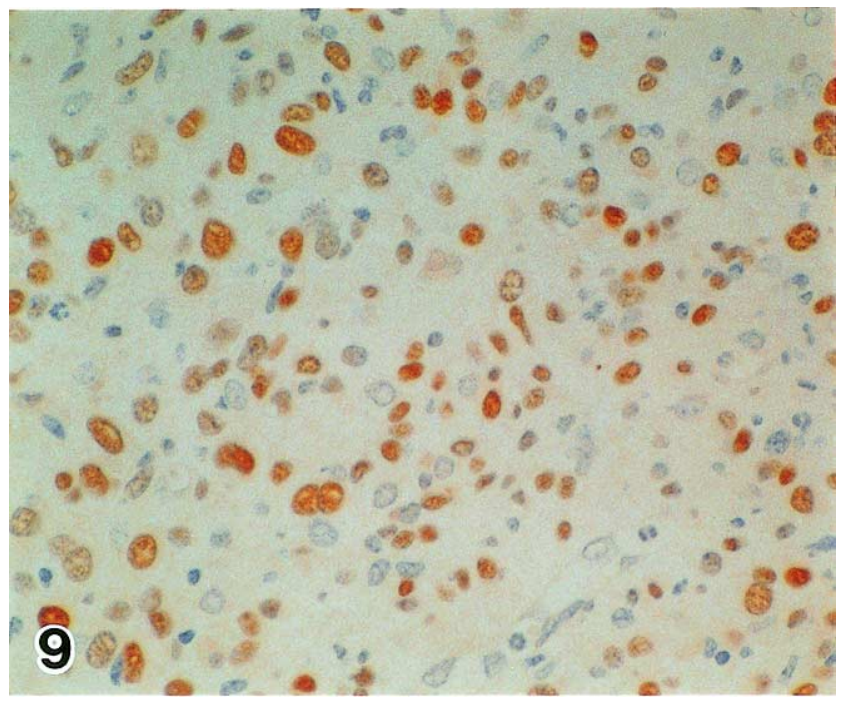

Fig. 9. Immunohistochemistry for $p 53$ in a uterine endometrial sarcoma from a $p 53(+/-)$ female mouse given ENU+1 ppm $\mathrm{EE}$ and sacrificed at week 26. Note overexpression of $p 53$ in the strongly proliferative area. $p 53$ immunostaining, $\times 330$.

depends on the morphology of the lesion and PCNA immunoreactivity ${ }^{23}$. On the other hand, Youssef et al. reported that while a good correlation was evident between PCNA and cyclin D1 overexpression in papillomas in a rat esophageal carcinogenesis model, this was not the case for carcinomas $^{24}$. Accordingly, expression of cyclin D1 may not simply be a direct consequence of increased cell proliferation ${ }^{25}$. Which other factors might also contribute remains to be clarified.

The overexpression of $p 53$ protein limited to strongly proliferative areas of uterine stromal sarcomas, indicated that mutations of $p 53$ may occur at a late stage in their development, associated with malignancy ${ }^{26}$. We have demonstrated that uterine endometrial stromal sarcomas induced by a single intraperitoneal administration of ENU to p53 (+/-) mice and have GCG to GTG transitions at codon 135 in all cases ${ }^{5}$. Since gene analysis was not performed in the present study, it cannot be concluded that all the cells with overexpression of $p 53$ showed mutation gene. However, most of them would be mutated cells taking into account the facts that mutant $p 53$ protein, produced by malignant cells, has a significantly prolonged half-life compared to the wild-type $p 53$ protein and therefore may reach a concentration in the cells that allows immunohistochemical detection. This could be a key phenomenon, given the important role in regulation of the G1 phase of the cell cycle ${ }^{4,14}$. Marx has postulated that $p 53$ $(+/-)$ mice might produce reduced amounts of $p 53$ protein after DNA damage, resulting in less p53-dependent p21, a cyclin-dependent kinase inhibitor, and consequently a higher susceptibility to carcinogens than wild-type mice ${ }^{27}$.

Overexpression of cyclin D1 was here detected at high incidences in uterine stromal sarcomas, as well as clear cell type atypical hyperplasias and an adenocarcinoma, in line with the evidence that it is an indicator of malignancy ${ }^{3}$. The present results point to progression from clear cell type atypical hyperplasias to endometrial adenocarcinomas, and suggest that clear cell type atypical hyperplasia acquires more malignant nature than basophilic cell atypical hyperplasia. Chemicals-induced uterine adenocarcinomas and atypical hyperplasias have been documented to occur in ICR mice given $17 \beta$-estradiol for 15 to 20 weeks after initiation of $\mathrm{MNU}$ or ENU ${ }^{28-30}$. These atypical hyperplasias in ICR mice had a morphological resemblance to those observed in our study. The data thus strongly indicate that EE exerts tumor-promoting effects on the endometrial epithelial cells as well as stromal cells of the uterus. In contrast, spontaneously occurring uterine adenocarcinomas are not common in laboratory mice. Histologically, such adenocarcinomas are characterized by no clear cell type cytoplasm, varying degrees of pleomorphism, atypia, and high mitotic rate, and are highly invasive ${ }^{31}$. Therefore, it is unlikely that this pathogenesis could be applied to all the events of mouse uterine carcinogenesis. Documentation concerning overexpression of cyclin D1 in rat esophagea ${ }^{24}$, hamster lung ${ }^{32}$, rat or mouse urinary bladder ${ }^{33}$, mouse skin ${ }^{34}$, and rat or mouse mammary lesions ${ }^{25}$ similarly pointed to be a role in progression toward malignancy. While the question arises as to why mutations of $p 53$ were not observed in clear cell type atypical hyperplasias and adenocarcinoma that were positive for cyclin D1, Hayashi et al. demonstrated overexpression of cyclin D1, but not $p 53$, in hamster lung tumors caused by N-methyl-N-nitrosourethane ${ }^{32}$. Trukhanova et al. have described p53 mutations in malignant fibrous histiocytomas, but not in uterine sarcomas due to 1,2-dimethylhydrazine in CBA mice ${ }^{35}$. These observations indicate that expression of cyclin D1 and p53 mutations may not always develop. With regard to absence of $p 53$ expression in proliferative lesions such as clear cell type atypical hyperplasias and adenocarcinoma, our ideas are as follows. Currently, about 50 oncogenes and 50 tumor suppressor genes are estimated to exist, and activation of 2 oncogenes or more and inactivation of 2 tumor suppressor genes or more have been postulated to be pivotal for carcinogenesis $^{36}$. Considering that mutations of $p 53$ protein have been generally reported in a wide variety of malignant tumors in humans ${ }^{7-13}$, further investigations are needed, but above facts suggest that mutations of tumor suppressor genes other than $p 53$ may occur in the present case.

There is correlation between dose levels of EE and occurrence of uterine proliferative lesions, but it seems there is no apparent correlation between dose levels of EE and overexpression of cyclin D1 and p53. Comparison of lesions with these overexpression between two groups indicates no difference on the staining mode. Considering that the number of animals with overexpression of cyclin D1 and $p 53$ in ENU+2.5 ppm EE group is slightly greater than that for ENU+1 ppm EE group, it is speculated that dose levels of EE may be responsible for transformation to malignancy of cells, although further investigations may be needed for exemplifying this. 
In conclusion, the present study indicates that cyclin D1 and p53 may play key roles in malignant transformation of uterine proliferative lesions. On the other hand, our previous study ${ }^{6}$ demonstrated that wild type mice receiving the ENU+ EE treatments developed uterine proliferative lesions comprising endometrial stromal polyps, atypical hyperplasias (clear and basophilic cell types) and glandular hyperplasias. Taken together the present immunohistochemical findings in $p 53(+/-)$ mice, there is the possibility that cyclin D1 may be also overexpressed in clear cell type atypical hyperplasias in the ENU+ EE groups of wild type mice. Therefore, further immunohistochemical study is needed to clarify the staining mode of cyclin D1 or p53 on uterine proliferative lesions induced in wild type mice.

Acknowledgements: The authors thank Dr. Shim-mo Hayashi, Molecular Pharmacology Laboratories, Takeda Chemical Industries, Ltd. for his expert assistance with the immunohistochemistry.

\section{References}

1. Ozaki K, Sukata T, Yamamoto S, Uwagawa S, Seki T, Kawasaki H, Yoshitake A, Wanibuchi H, Koide A, Mori Y, and Fukushima S. High susceptibility of $p 53$ (+/-) knockout mice in $\mathrm{N}$-butyl-N-(4-hydroxybuytl)nitrosamine urinary bladder carcinogenesis and lack of frequent mutation in residual allele. Cancer Res 1998; 58: 3806-3811.

2. Tennant RW, French JE, and Spalding JW. Identifying chemical carcinogens and assessing potential risk in shortterm bioassays using transgenic mouse models. Envion Health Persp 1995; 103: 942-950.

3. Donehower LA, Harvey M, Slagle B, McArthur MJ, Montogomery Jr CA, Butel JS, and Bradley A. Mice deficient for $p 53$ are developmentally normal but susceptible to spontaneous tumours. Nature 1992; 356: 215-221.

4. Fukasawa K, Wiener F, Woude GFV, and Mai S. Genomic instability and apoptosis are frequent in $p 53$ deficient young mice. Oncogene 1997; 15: 1295-1302.

5. Mitsumori K, Onodera H, Shimo T, Yasuhara K, Takagi H, Koujitani T, Hirose M, Maruyama C, and Wakana S. Rapid induction of uterine tumors with $p 53$ point mutations in heterozygous p53 deficient CBA mice given a single intraperitoneal administration of N-ethyl-N-nitrosourea. Carcinogenesis 2000; 21: 1039-1042.

6. Mitsumori K, Shimo T, Onodera H, Takagi H, Yasuhara K, Tamura T, Aoki Y, Nagata O, and Hirose M. Modifying effects of ethinylestradiol but not methoxychlor on N-ethyl$\mathrm{N}$-nitrosourea-induced uterine carcinogenesis in heterozygous $p 53$ deficient CBA mice. Toxicol Sci. in press.

7. Fujimoto K, Yamada Y, Okajima E, Kakizoe T, Sasaki H, Sugimura T, and Terada M. Frequent association of $p 53$ gene mutation in invasive bladder cancer. Cancer Res 1992; 52: 1393-1398.

8. Sato T, Okazaki A, Okazaki M, Takahashi S, and Hirata K. Detection of $p 53$ gene mutations in aspirin biopsy specimens from suspected breast cancer by polymerase chain reactionsingle strand conformation polymorphism analysis. Jpn J Cancer Res 1995; 86: 140-145.

9. Hollstein MC, Metcalf RA, Welsh JA, Montesano R, and
Harris CC. Frequent mutation of the $p 53$ gene in human esophageal cancer. Proc Natl Acad Sci USA 1990; 87: 9958-9961.

10. Tamura G, Kihana T, Nomura K, Terada M, Sugimura T, and Hirohashi S. Detection of frequent $p 53$ gene mutations in primary gastric cancer by cell sorting and polymerase chain reaction single-strand conformation polymorphism analysis. Cancer Res 1991; 52: 3056-3058.

11. Takahashi T, Nau MM, Chiba I, Birrer MJ, Rosenberg RK, Vinocour M, Levitt M, Pass H, Gazdar AF, and Minna JD. p53: frequent target for genetic abnormalities in lung cancer. Science 1989; 246: 491-494.

12. Tsuda $\mathrm{H}$, Jiko $\mathrm{K}$, Tsugane $\mathrm{S}$, Yajima $\mathrm{M}$, Yamada $\mathrm{T}$, Tanemura K, Tsunematsu R, Ohmi K, Sonoda T, and Hirohashi S. Prognostic value of $p 53$ protein accumulation in cancer cell nuclei in adenocarcinoma of the uterine cervix. Jpn J Cancer Res 1995; 86: 1049-1053.

13. Watanabe M, Ushijima T, Kakiuchi H, Shiraishi T, Yatani R, Shimazaki J, Kotake T, Sugimura T, and Nagao M. p53 gene mutations in human prostate cancers in Japan: Different mutation spectra between Japan and western countries. Jpn J Cancer Res 1994; 85: 904-910.

14. Hartwell LH, and Kastan MB. Cell cycle control and cancer. Science 1994; 266: 1821-1828.

15. Cross SM, Sanchez CA, Morgan CA, Schmike MK, Ramel S, Idzerda RL, Raskind WH, and Reid BJ. A p53-dependent mouse spindle checkpoint. Science 1995; 267: 1353-1356.

16. Grana $X$ and Reddy EP. Cell cycle control in mammalian cells: role of cyclins, cyclin dependent kinases (CDKs), growth suppressor genes and cyclin-dependent kinase inhibitors (CKIs). Oncogene 1995; 11: 211-219.

17. Nurse P. Universal control mechanism regulating onset of M-phase. Nature 1990; 344: 503-508.

18. Sherr CJ. Mammalian G1 cyclins. Cell 1993; 73: 1059-1065.

19. Nishida N, Fukuda $Y$, Komeda $T$, Kita $R$, Sando $T$, Furukawa M, Amenomori M, Shibagaki I, Nakao K, Ikenaga $\mathrm{M}$, and Ishizaki K. Amplification and overexpression of the cyclin D1 gene in aggressive human hepatocellular carcinoma. Cancer Res 1994; 54: 3107-3110.

20. Withers DA, Harvey RC, Faust JB, Melnyk O, Carey K, and Meeker TC. Characterization of a candidate bcl-1 gene. Mol Cell Biol 1991; 11: 4846-4853.

21. Shuuring E, Verhoeven E, Mooi WJ, and Michalides RJAM. Identification and cloning of two overexpressed genes, U21B31/PRAD1 and EMS1, within the amplified chromosome 11q13 region in human carcinomas. Oncogene 1992; 7: 355-361.

22. Yoshida T, Sakamoto H, and Terada M. Amplified genes in cancer in upper digestive tract. Semin Cancer Biol 1993; 4: $33-40$.

23. Wolf DC, Gross EA, Lyght O, Bermudez E, Recio L, and Morgan KT. Immunohistochemical localization of $p 53$, PCNA, and TGF-alpha proteins in formaldehyde-induced rat nasal squamous cell carcinomas. Toxicol Appl Pharmacol 1995; 132: 27-35.

24. Youssef EM, Hasuma T, Morishima Y, Takada N, Osugi H, Higashino M, Otani S, and Fukushima S. Overexpression of cyclin D1 in rat esophageal carcinogenesis model. Jpn J Cancer Res 1997; 88: 18-25.

25. Sgambato A, Kyu-Ho Han E, Zhang Y, Moon RC, Santella RM, and Weinstein IB. Deregulated expression of cyclin D1 and other cell cycle-related genes in carcinogen-induced rat 
mammary tumors. Carcinogenesis 1995; 16: 669-671.

26. Walker RA, Dearing SJ, Lane DP, and Varley JM. Expression of $p 53$ protein in infiltrating and in-situ breast carcinomas. J Pathol 1991; 165: 203-211.

27. Marx J. How p53 suppresses cell growth. Science 1993; 262: 1644-1645.

28. Niwa K, Tanaka T, Mori H, Yokoyama Y, Furui T, Mori H, and Tayama T. Rapid induction of endometrial carcinoma in ICR mice treated with $\mathrm{N}$-methyl-N-nitrosourea and $17 \beta$ estradiol. Jpn J Cancer Res 1991; 82: 1391-1396.

29. Takahashi M, Iijima T, Suzuki K, Ando-Lu J, Yoshida M, Kitamura T, Nishiyama K, Miyajima K, and Maekawa A. Rapid and high yield induction of endometrial adenocarcinomas in CD-1 mice by a single intra-uterine administration of $\mathrm{N}$-ethyl-N-nitrosourea combined with chronic $17 \beta$-estradiol treatment. Cancer Lett 1996; 104: 7-12.

30. Maekawa A, Takahashi M, Ando J, and Yoshida M. Uterine carcinogenesis by chemical/hormones in rodents. J Toxicol Pathol 1999; 12: 1-11.

31. Faccini JM, Abbott DP, and Paulus GJJ. IX. Female genital tract. In: Mouse Histopathology, Elsevier, 147-168, 1990.

32. Hayashi S, Mitsumori K, Yasuhara K, Mori I, Imazawa T, Onodera H, Nonoyama T, Takahashi M, and Hayashi Y.
Significance of cyclin D1 overexpression and $K$-ras point mutations in lung tumors induced by N-methyl-Nnitrosourethane in hamsters. J Toxicol Pathol 1997; 10: 137143.

33. Yamamoto S, and Fukushima S. Alterations of cell cycle regulators in rat and mouse urinary bladder carcinogenesis models. J Toxicol Pathol 1997; 10: 125-127.

34. Mitsunaga SL, Zhang SY, Ruggeri BA, Gimenez-Conti I, Robles AI, Conti CJ, and Klein-Szanto AJP. Positive immunohistochemical staining of p53 and cyclin D in advanced mouse skin tumors, but not in precancerous lesions produced by benzo(a) pyrene. Carcinogenesis 1995; 16: $1629-1635$.

35. Trukhanova LS, Hong HHL, Sills RC, Bowser AD, Gual B, Boorman GA, Trusov VS, Devereux TR, and Dixon D. Predominant $p 53 \mathrm{G}$ to A transition mutation and enhanced cell proliferation in uterine sarcomas of CBA mice treated with 1, 2-dimethylhydrazine. Toxicol Pathol 1998; 26: 367374.

36. Taya $\mathrm{Y}$, Noda $\mathrm{M}$, and Yamamoto T. H. 1.Oncogene and suppressor tumor gene and 7. Multi-phase carcinogenesis. In: Hunting of Oncogene, Taya Y (ed), Yodosha, 12-27, 99$102,1995$. 